\title{
A new diastereoselective approach to the synthesis of $\alpha$-hydroxy- $\beta$-amino acids based on the frame of captodative olefins
}

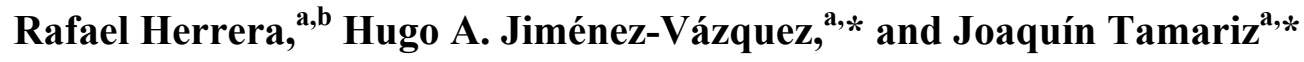 \\ ${ }^{a}$ Departamento de Química Orgánica, Escuela Nacional de Ciencias Biológicas, Instituto \\ Politécnico Nacional, Prol. Carpio y Plan de Ayala, 11340 México, D.F., Mexico. ${ }^{b}$ Instituto de \\ Investigaciones Quimicobiológicas, Universidad Michoacana de San Nicolás de Hidalgo, Edif. \\ B-1, Ciudad Universitaria, Francisco J. Mujica S/N, 58066 Morelia, Mich., Mexico. \\ E-mail: jtamariz@,woodward.encb.ipn.mx
}

\section{Dedicated to Professor Eusebio Juaristi on his $55^{\text {th }}$ birthday}

(received 22 Apr 05; accepted 07 Jun 05; published on the web 20 Jun 05)

\begin{abstract}
A new diasteroselective approach for the preparation of chiral $\alpha$-hydroxy- $\beta$-amino acids is described. It is based on the conjugate addition of either $(R)-(+)$-methylbenzylamine (4) or its lithium salt to the captodative olefins: methyl 2-aroyloxy- and 2-methacryloxy acrylates, 1a-1b and 1c. The highest diastereoselectivity is obtained when the addition is carried out with the chiral lithium amide in the presence of trialkylsilyl chlorides.
\end{abstract}

Keywords: $\alpha$-Hydroxy- $\beta$-amino acids, captodative olefins, conjugate addition, $(R)-(+)-$ methylbenzylamine

\section{Introduction}

$\beta$-Amino acids are crucial components of natural peptides and biologically active products such as $\beta$-lactam antibiotics. ${ }^{1}$ A wide spectra of synthetic methodology is available for their preparation. ${ }^{2}$ In particular, $\alpha$-hydroxy- $\beta$-amino acids have attracted especial attention owing to their essential role in promoting the activity of some medicinally important drugs, among them the antitumoral Taxol ${ }^{\circledR}$ and derivatives, ${ }^{3}$ or the antihypertensive agent KRI-1314. ${ }^{4}$ Several strategies have been developed for the synthesis of these compounds, including as key steps such as: the Lewis acid-catalyzed diastereoselective aldol-type reaction of chiral imines with ketene silyl acetals; ${ }^{5}$ the chiral epoxidation of (Z)-cinnamyl alcohol ${ }^{6}$ or $(Z)$-ethyl cinnamate, ${ }^{7}$ and subsequent epoxide cleavage by addition of ammonia, amine, or azide ion; the dihydroxylation of methyl $(E)$-cinnamate with the corresponding chiral osmium catalyst, followed by the regioselective introduction of the amino group at the beta position; ${ }^{8}$ the asymmetric alpha 
hydroxylation of $\beta$-amino acids by using $(+)$-(camphorsulfonyl)oxaziridine; ${ }^{9}$ among other methodologies. ${ }^{10}$<smiles>[R]OC(=O)C(=C)OC(=O)O</smiles>

1, $\mathrm{R}=\mathrm{Me}$

2, $R=E t$<smiles>C=C(OC(=O)OC)C(=O)OC</smiles>

1a, $\mathrm{Ar}=\mathrm{C}_{6} \mathrm{H}_{4} p-\mathrm{NO}_{2}$

1b, $\mathrm{Ar}=\mathrm{C}_{6} \mathrm{H}_{4} p-\mathrm{Br}$<smiles>C=C(C)C(=O)OC(=C)C(=O)OC</smiles>

1c

As a part of our interest in the study of reactivity ${ }^{11}$ and synthetic applications ${ }^{12}$ of captodative olefins, we reported the synthesis of the methyl and ethyl 2-aroyloxyacrylates, 1 and 2, which proved to be highly reactive and regioselective as dienophiles in Diels-Alder additions. ${ }^{13}$ Considering that these alkenes carry a potential alpha hydroxyl group, and that they might undergo Michael additions of amines, ${ }^{14}$ a synthesis of protected $\alpha$-hydroxy- $\beta$-amino acids (3) could be designed aiming to functionalize the vicinal diastereoisomeric centers in one step (Scheme 1). Therefore, we hereby describe the study of reactivity and diastereoselectivity of olefins 1a-1c in the addition of a chiral amine $\mathbf{4}$ under diverse reaction conditions, as a new approach to the asymmetric synthesis of $\alpha$-hydroxy- $\beta$-amino acids.<smiles>[R]NCC(OC([R])=O)C(=O)OC</smiles>

3
NHR

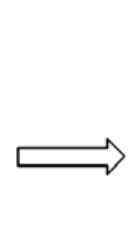

$\sqrt{2}$

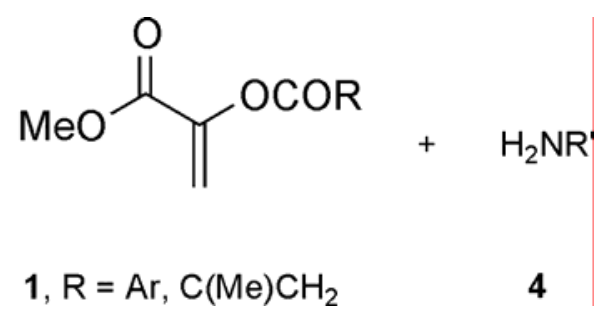

\section{Scheme 1}

\section{Results and Discussion}

The strategy depicted in Scheme 1 is based on the well-known addition of chiral amines to Michael acceptors to yield the $\beta$-amino carbonyl compounds. ${ }^{2 b, 15}$ Assuming that a chiral amine such as $(R)-(+)$-methylbenzylamine (4a) could add to alkenes 1a-1c, the asymmetric $\alpha$ aroyloxy(methacryloxy)- $\beta$-amino esters (3) would be obtained. Further transformation of the latter to the $\alpha$-hydroxy- $\beta$-amino acids could be feasibly achieved. Therefore, we focused our efforts on the optimization of the efficiency and diastereoselectivity of the first reaction.

The captodative olefin 1a was prepared as previously described, ${ }^{13}$ by reaction of methyl pyruvate with the corresponding acyl chloride in the presence of triethylamine. When 1a was treated with $4 \mathbf{a}$ in THF at room temperature for $4 \mathrm{~h}$, a mixture of the diastereomeric adducts 
5a/6a (66:34) and amide 7a was obtained in a ratio of 7:3 (Scheme 2). It is noteworthy that, even though part of the addition of the amine occurred at the $p$-nitrobenzoyloxy ester, giving amide 7a, most of the product corresponded to the 1,4-addition to the acrylate moiety, providing diastereomers 5a/6a. The ratio of the latter was slightly in favor of the $(R, R)$ isomer 5a (Table 1 , entry 1).

The addition of 2.0 mol equiv. of HMPA as a polar co-solvent did not improve the asymmetric induction; however, the proportion of the byproduct $7 \mathbf{a}$ was largely increased (Table 1, entry 2). Similar results were observed when ethyl ether was used as solvent instead (Table 1, entries 3 and 4).

Microwave irradiation in water as the medium has been used to increase the efficiency of the 1,4-addition of amines to carbonyl compounds. ${ }^{16}$ Thus, we carried out the reaction in water under MW irradiation for $20 \mathrm{~min}$. Even though the attack on the ester to give amide 7a was reduced, no diastereomeric excess (de) was observed (Table 1, entry 5).

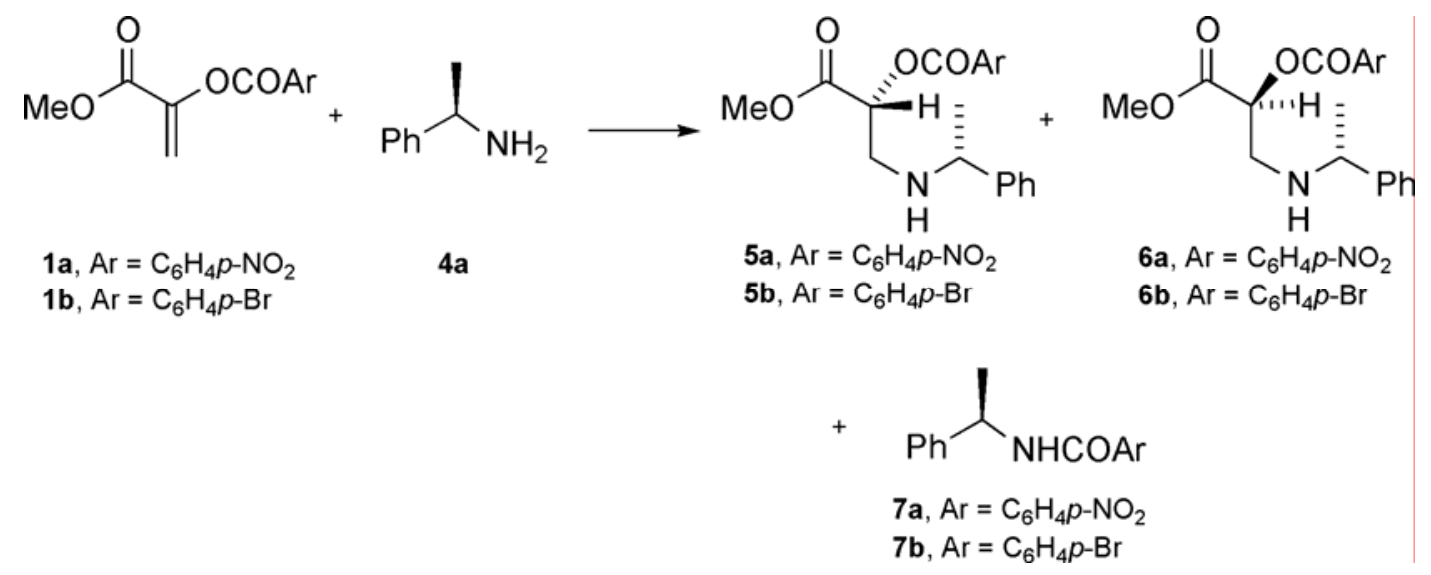

\section{Scheme 2}

The use of $\mathrm{Pd}(\mathrm{II})$ catalysts has proven to promote 1,4-additions of amines to Michael acceptors as well. ${ }^{17}$ Therefore, amine $4 \mathbf{a}$ was made to react with $1 \mathbf{a}$ in the presence of $20 \mathrm{~mol} \%$ $\mathrm{Pd}(\mathrm{OAc})_{2}$ (Table 1, entry 6). However, no significant asymmetric induction was observed, and the decomposition of the olefin by addition of the amine to the ester was the major process.

In accord with the results summarized in Table 1, olefin 1a was found to react with amine 4a to give a mixture of the diastereomeric 1,4-addition products $\mathbf{5 a} / \mathbf{6 a}$. The higher diastereoselection was found in the absence of additive, also reducing the amount of the addition byproduct 7a. It is likely that the formation of the latter be favored by the presence of the nitro group in the aromatic ring of the ester. Hence, we prepared the new captodative olefin $\mathbf{1 b}$, which bears a bromine atom as substituent in the aryl ring, in order to lower the activating effect on the ester carbonyl group, and, consequently, to reduce the addition of the amine to this site. 
Table 1. Diastereoselectivity in the 1,4-additions of $\mathbf{4 a}$ to olefin $\mathbf{1 a}^{a}$

\begin{tabular}{ccccccc}
\hline Entry & Olefin & Solvent & Additive $^{b}$ & $\mathbf{5}+\mathbf{6} / \mathbf{7}^{c}$ & $\mathbf{5} / \mathbf{6}^{c}$ & Yield (\%) $^{d}$ \\
\hline 1 & 1a & THF & --- & $70: 30$ & $66: 34$ & 46 \\
2 & 1a & THF & HMPA & $50: 50$ & $60: 40$ & 27 \\
3 & 1a & Et2O & --- & $50: 50$ & $64: 36$ & 31 \\
4 & 1a & Et2O & HMPA & $55: 45$ & $65: 35$ & 35 \\
5 & 1a & H2O & MW & $70: 30$ & $51: 49$ & 44 \\
6 & 1a & CH2Cl2 & Pd(OAc)2 & $40: 60$ & $56: 44$ & 22 \\
7 & 1b & THF & --- & $70: 30$ & $56: 44$ & 50 \\
\hline
\end{tabular}

${ }^{a}$ All under $\mathrm{N} 2$ atmosphere, at $25{ }^{\circ} \mathrm{C}$ for $24 \mathrm{~h} .{ }^{b} 2.0$ mol equiv. of HMPA. $20 \mathrm{~mol} \%$, of $\mathrm{Pd}(\mathrm{OAc}) 2.200 \mathrm{~W}$ in MW irradiation. ${ }^{c}$ Proportions as determined by ${ }^{1} \mathrm{H}$ NMR of the crude reaction mixtures. ${ }^{d}$ As a mixture of isomers $\mathbf{5 / 6}$ after purification by column chromatography. ${ }^{e}$ Not determined.

Unexpectedly, the reaction of $\mathbf{1 b}$ with chiral amine $\mathbf{4 a}$ in THF at $25^{\circ} \mathrm{C}$ for $4 \mathrm{~h}$ yielded a ratio of 1,4-addition and ester addition products, $\mathbf{5 b}+\mathbf{6 b} / \mathbf{7 b}$, comparable to that found with olefin 1a (Table 1, entries 1 and 7). In addition, the diastereoselection was lower in this case, since the ratio of $\mathbf{5 b} / \mathbf{6} \mathbf{b}$ was only $56: 44$.

With the aim of explaining these results and of designing a lesser activated ester, we analyzed the Mülliken charges of these olefins, and of the acrylate analogue 1c. Table 2 summarizes the charges $\left(\mathrm{HF} / 6-31 \mathrm{G}^{* *}\right)$ at the reactive sites $\mathrm{C}-1, \mathrm{C}-3, \mathrm{C}-4$, and $\mathrm{C}-6$. It is interesting to notice that, for the aroyloxy captodative olefins $\mathbf{1 a - 1 b}$ and $\mathbf{1 d}$, carbon $\mathrm{C}-4$ is slightly more positive than carbon $\mathrm{C}-1$, which could explain the fact that the amine adds to C-4 instead of C-1. Surprisingly, these values also suggest a preferential addition to the ester carbon $\mathrm{C}-4$ with respect to a conjugate addition to $\mathrm{C}-3$, since the latter is electron-rich. It is likely that the 1,4-addition products $\mathbf{5}$ and $\mathbf{6}$ arise from a high interaction energy between carbon C-3 and the nitrogen atom of the amine as a consequence of a mutual donation, as predicted for the 1,3dipolar additions with nitrones. ${ }^{11 \mathrm{~b}}$ The presence of an electron-donating group in the benzene ring in alkene 1d reduces just a little the electropositive character of carbon C-4 with respect to olefin 1a. An analogous trend is observed for olefin 1b, a fact that can explain the similar behavior in the addition of the amine to C-4 in both cases (Table 1).

For olefin 1c, carbon $\mathrm{C}-4$ is only a little more positive than $\mathrm{C}-1$ (Table 2). Therefore, it is expected that the addition of the amine to $\mathrm{C}-4$ of $\mathbf{1 c}$ be less important than for olefins $\mathbf{1 a - 1 b}$ and 1d. With respect to the conjugate addition of the amine to the beta positions of the acrylic moieties in 1c, the lower negative charge of carbon C-6 could predict a preferential attack of the amine to this carbon and not to carbon C-3 (Table 2). 
Table 2. Calculated Mülliken charges $\left(\mathrm{HF} / 6-31 \mathrm{G}^{* *}\right)^{a}$ for alkenes 1a-1d<smiles>C=C(OC(=O)Br)C(=O)OC</smiles>

1a, $\mathrm{Ar}=\mathrm{C}_{6} \mathrm{H}_{4}-p-\mathrm{NO}_{2}$

1b, $\mathrm{Ar}=\mathrm{C}_{6} \mathrm{H}_{4}-p-\mathrm{Br}$

1d, $\mathrm{Ar}=\mathrm{C}_{6} \mathrm{H}_{4}-\mathrm{p}-\mathrm{OMe}$<smiles>C=C(C)C(=O)OC(=C)C(=O)OC</smiles>

1c

\begin{tabular}{ccccc}
\hline Alkene & C-1 & C-3 & C-4 & C-6 \\
\hline 1a & 0.812 & 0.076 & 0.876 & ----- \\
1b & 0.811 & 0.067 & 0.870 & ----- \\
1c & 0.809 & 0.060 & 0.828 & 0.057 \\
1d & 0.808 & 0.057 & 0.869 & ----- \\
\hline
\end{tabular}

${ }^{a}$ The charges are average values obtained among the most stable conformers ( 4 for $\mathbf{1 c}$, and 2 for the others), which have very similar energies, at least at this level of theory. ${ }^{b}$ The charges of the attached hydrogen atoms have been added to the charges of the carbon atoms.

Therefore, with the interest to investigate the chemoselectivity of the addition of the chiral amine 4a to 1c, this bis-captodative alkene was prepared in high yield (90\%) by treating methyl pyruvate with methacryloyl chloride in THF at $-50{ }^{\circ} \mathrm{C}$, and stirring at room temperature for $24 \mathrm{~h}$. Indeed, when the reaction of 1c was carried out in the presence of amine $4 \mathbf{a}$, the product of addition to carbon C-4 was reduced to $15 \%$, as suggested by the charges at this carbon; however, in contrast to the expected chemoselectivity, the 1,4-addition to carbon C-3 was exclusive (Scheme 3). A mixture of diasteroisomers 5c and $\mathbf{6 c}$ was obtained (71\%) with low selectivity (55:45), and no product from the C-6 addition was detected by NMR. This result confirms the higher reactivity of the captodative $\mathrm{C}-2 / \mathrm{C}-3$ double bond in comparison with the captodative $\mathrm{C}$ 5/C-6 olefin, as shown in Diels-Alder cycloadditions and Friedel-Crafts reactions for analogous compounds. $^{18}$

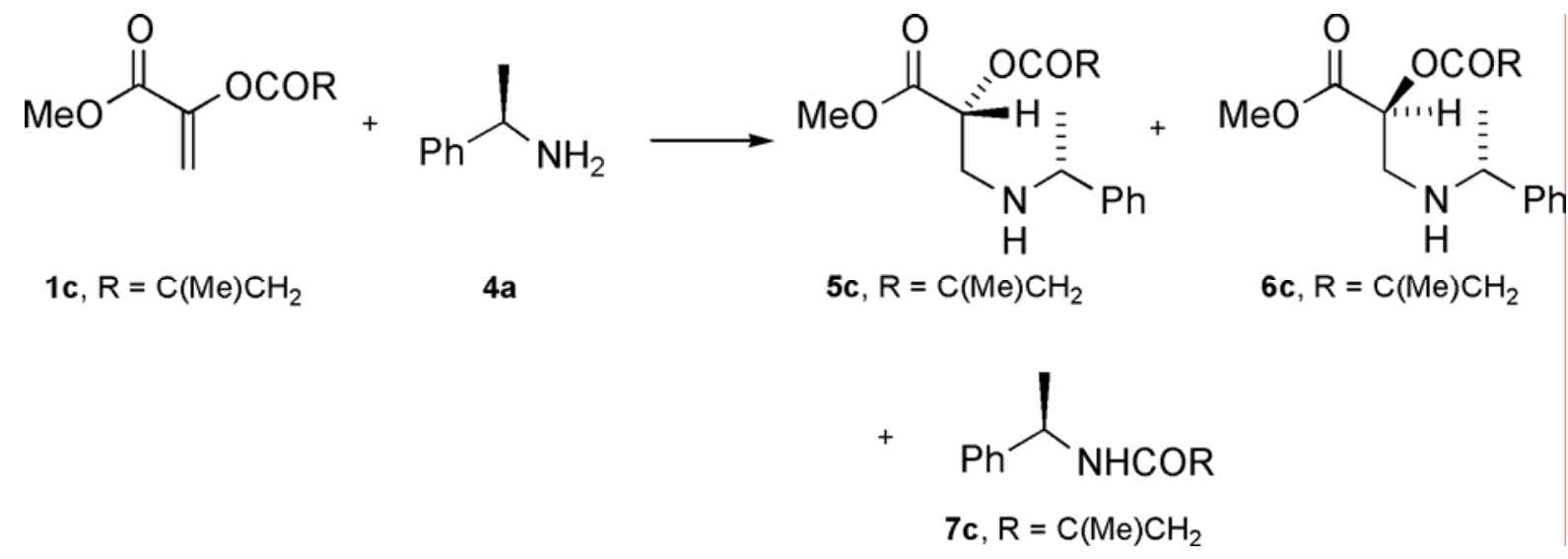

Scheme 3 
Considering that the 1,4-addition can be favorably promoted by secondary amines, which in turn can be generated by silylating primary amines, ${ }^{19}$ we carried out the reaction mentioned above in the presence of different alkyl- and alkylphenyl silyl chlorides, 8a-8c (Table 3). Consequently, the lithium amide of amine $\mathbf{4 a}$, prepared by deprotonation with $n$-BuLi, was mixed with 8 at $-50{ }^{\circ} \mathrm{C}$ in anhydrous THF; after stirring the mixture for $30 \mathrm{~min}$, the substrate 1a was added, and the reaction mixture was maintained at $25{ }^{\circ} \mathrm{C}$ for $24 \mathrm{~h}$. Both, the proportion of amide $7 \mathbf{a}$ and the ratio of the stereoisomeric adducts $\mathbf{5 a} / \mathbf{6 a}$, were similar in the three cases, showing a slight dependence on the silyl compound used in the reaction (Table 3, entries 1-3).

Contrary to our expectations, adducts 5a and 6a did not incorporate the silyl group after reacting the chiral amine with the corresponding silyl chloride. ${ }^{20}$ In all cases, we were unable to detect, by NMR, the silylated amine in the crude mixtures. It appears that the acidic conditions of the workup are strong enough to cleave the acid-sensitive N-Si bond. ${ }^{19,20}$ However, the diastereomeric excess and the chemoselectivity were increased with respect to the unsilylated reaction conditions in THF, suggesting that the silane participates in the reaction. Furthermore, when the reaction was carried out in the presence of $\mathbf{8 a}$, using ethyl ether as solvent, the de of 5a/6a was the best and the chemical yield was high (Table 3, entry 4). Nevertheless, under the same solvent conditions, silyl chlorides $\mathbf{8 b}$ and $\mathbf{8 c}$ did not improve the diastereoselectivity, and the attack to the ester group was increased (Table 3, entries 5 and 6).

Table 3. Diastereoselectivity in the 1,4-additions of the amide of $\mathbf{4 a}$ to the olefin $\mathbf{1 a}$ in the presence of the silyl chlorides 8a-8c ${ }^{a}$

\begin{tabular}{|c|c|c|c|c|c|c|}
\hline Entry & $\mathbf{8}^{b}$ & Solvent & Co- & $5+6 / 7^{c}$ & $5 \mathbf{a} / 6 \mathbf{a}^{c}$ & Yield $(\%)^{d}$ \\
\hline 1 & $8 \mathbf{a}$ & THF & --- & $63: 37$ & $63: 37$ & 63 \\
\hline 2 & $8 b$ & THF & --- & $62: 38$ & $69: 31$ & 78 \\
\hline 3 & $8 c$ & $\mathrm{THF}$ & --- & $66: 34$ & $65: 35$ & 61 \\
\hline 4 & $\mathbf{8 a}$ & $\mathrm{Et} 2 \mathrm{O}$ & --- & $74: 26$ & $73: 27$ & 80 \\
\hline 5 & $8 b$ & Et2O & --- & $41: 59$ & $65: 35$ & 85 \\
\hline 6 & $8 c$ & Et2O & --- & $55: 45$ & $58: 42$ & 69 \\
\hline 7 & $\mathbf{8 a}$ & Et2O & HMPA & $40: 60$ & $59: 41$ & 50 \\
\hline 8 & $8 b$ & Et2O & HMPA & $54: 46$ & $68: 32$ & 60 \\
\hline 9 & $\mathbf{8 a}$ & $\mathrm{THF}$ & HMPA & $72: 28$ & $55: 45$ & 83 \\
\hline 10 & $8 b$ & THF & HMPA & $70: 30$ & $67: 33$ & 77 \\
\hline 11 & $8 c$ & $\mathrm{THF}$ & HMPA & $39: 61$ & $57: 43$ & 83 \\
\hline
\end{tabular}

${ }^{a}$ All under $\mathrm{N} 2$ atmosphere, with $1.0 \mathrm{~mol}$ equiv. of $n$-BuLi and $1.0 \mathrm{~mol}$ equiv. of the silyl chloride 8, at $-50{ }^{\circ} \mathrm{C}$ for $4 \mathrm{~h}$, then at $25{ }^{\circ} \mathrm{C}$ for $24 \mathrm{~h} .{ }^{b} t$-butyldimethylsilyl chloride (8a), trimethylsilyl chloride (8b), and diphenylmethylsilyl chloride (8c). ${ }^{c}$ Proportions as determined by $1 \mathrm{H}$ NMR of the crude reaction mixtures. ${ }^{d}$ As a mixture of isomers after purification by column chromatography. 
Although the chemoselectivity of the reaction did not improve when HMPA was added to ether as a co-solvent (Table 3, entries 7 and 8), better results were obtained with THF was the solvent, since the amount of the amide byproduct 7a was reduced (Table 3, entries 9 and 10). However, in the presence of dimethylphenylsilyl chloride (8c) the content of amide $7 \mathbf{a}$ was the highest and the de was very low (Table 3 , entry 11 ).

The configuration of the major isomer 5 was established by $2 \mathrm{D}$ and nOe NMR experiments, supported by ab initio calculation of the most stable conformations. Selected chemical shifts, and the coupling constants employed to assign the configuration of the diastereomeric pairs $\mathbf{5 b} / \mathbf{6 b}$ and $\mathbf{5 c} / \mathbf{6 c}(2 R R / 2 S R)$, are listed in Table 4 . In all cases, the first order signals for the vicinal protons H-2, H-3a, and H-3b, consisted each of a very clear doublet of doublets with one gem $\left({ }^{2} J_{\mathrm{HH}}\right)$ and two vicinal coupling constants $\left({ }^{3} J_{\mathrm{HH}}\right)$, suggesting two possibilities: (a) A conformer much lower in energy than others with an intrinsic set of coupling constants, and (b) A set of several interconverting conformers with low rotational barriers and averaged coupling constants.

Table 4. Selected experimental and calculated chemical shifts and coupling constants for the ${ }^{1} \mathrm{H}$ NMR (300 MHz) spectra of the chiral compounds $\mathbf{5 b}, \mathbf{5 c}, \mathbf{6 b}$, and $\mathbf{6} \mathbf{c}^{a}$

\begin{tabular}{|c|c|c|c|c|c|c|}
\hline$\delta(\mathrm{ppm})$ & $\mathrm{H}-2^{b}$ & $\mathrm{H}-3 \mathrm{a}^{b}$ & $\mathrm{H}-3 \mathrm{~b}^{b}$ & $\mathrm{Ph}(\mathrm{Me}) \mathrm{CHN}$ & $\mathrm{Ph}(\mathbf{M e}) \mathrm{CHN}$ & $\mathrm{CO} 2 \mathrm{Me}$ \\
\hline $5 \mathbf{b}$ & 5.38 & 3.09 & 2.98 & 3.84 & 1.36 & 3.74 \\
\hline $5 c$ & 5.20 & 2.99 & 2.91 & 3.80 & 1.33 & 3.72 \\
\hline $6 \mathbf{b}$ & 5.34 & 3.12 & 3.02 & 3.85 & 1.38 & 3.76 \\
\hline $6 c$ & 5.16 & 3,01 & 2.93 & 3.80 & 1.34 & 3.74 \\
\hline$J \mathrm{H}-\mathrm{H}(\mathrm{Hz})$ & $\mathrm{H}-2 / \mathrm{H}-3 \mathrm{a}^{b}$ & $\mathrm{H}-2 / \mathrm{H}-3 \mathrm{~b}^{b}$ & H-3a/H- $3 b^{b}$ & $\mathrm{H}-2 / \mathrm{H}-3 \mathrm{a}^{c}$ & $\mathrm{H}-2 / \mathrm{H}-3 \mathrm{~b}^{c}$ & \\
\hline $5 b$ & 3.6 & 6.0 & 12.9 & $4.4^{d}$ & $5.2^{d}$ & \\
\hline $5 c$ & 3.6 & 6.6 & 12.9 & 4.4 & 5.2 & \\
\hline $6 \mathrm{~b}$ & 6.3 & 4.0 & 12.9 & $7.5^{d}$ & $3.1^{d}$ & \\
\hline $6 c$ & 6.6 & 4.5 & 12.9 & 7.5 & 3.1 & \\
\hline
\end{tabular}

${ }^{a}$ For further data, see the experimental section. ${ }^{b}$ Experimental. ${ }^{c}$ Calculated, see text. ${ }^{d}$ Assuming the conformational behavior of the $\mathbf{5 c / 6} \mathbf{c}$ system.

NOe experiments suggested a spatial proximity between the protons labeled as $\mathrm{H}-2$ and $\mathrm{H}-$ $3 \mathrm{a}$ (pro- $(S)$ ) for the $(2 R)$ isomers $\mathbf{5 b}$ and $\mathbf{5 c}$. For example, for $\mathbf{5 b}$, a magnitude enhancement of the signal attributed to proton $\mathrm{H}-2$ at 5.38 ppm was observed when the signal at $3.09 \mathrm{ppm}(\mathrm{H}-3 \mathrm{a})$ was irradiated. Also an enhancement was detected at the latter signal for the opposite irradiation (Figure 1). These enhancements were larger $(>6 \%)$ than those found $(<2 \%)$ between protons $\mathrm{H}$ 2 and the anti proton $\mathrm{H}-3 \mathrm{~b}$ (pro- $(R))$ at $2.98 \mathrm{ppm}$. On the other hand, for the $(2 S)$ isomer $\mathbf{6 b}$, the signal at $3.02 \mathrm{ppm}$ attributed to proton $\mathrm{H}-3 \mathrm{~b}$ showed a larger enhancement $(>5 \%)$ when the proton $\mathrm{H}-2$ was irradiated $(5.34 \mathrm{ppm})$, than that found $(<2 \%)$ for the irradiation of the anti 
proton $\mathrm{H}-3 \mathrm{a}$ (3.12 ppm), suggesting that for this isomer $\mathrm{H}-2$ is closer to H-3b. Similar nOe enhancements were found for isomers $\mathbf{5 c}$ and $\mathbf{6 c}$.

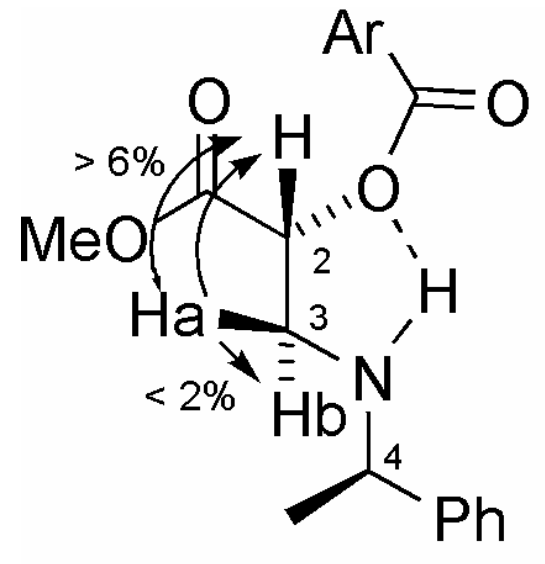

5b, $\mathrm{Ar}=\mathrm{C}_{6} \mathrm{H}_{4}-\mathrm{p}-\mathrm{Br}$

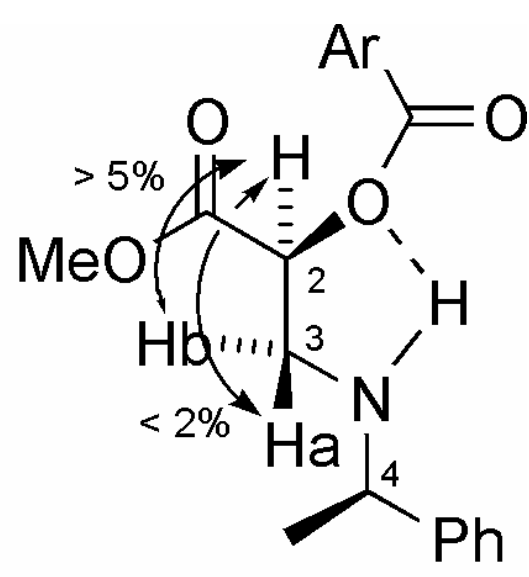

6b, $\mathrm{Ar}=\mathrm{C}_{6} \mathrm{H}_{4}-\mathrm{p}-\mathrm{Br}$

Figure 1. NOe's observed upon irradiation of protons in compounds $\mathbf{5 b}$ and $\mathbf{6 b}$.

In order to relate the experimental results to the conformational preference of these systems, we decided to determine the geometries of their most stable conformers. Conformational searches were carried out independently for the diastereomeric pair $\mathbf{5 c / 6 c}$ with the Monte Carlo method implemented in the Spartan program package, ${ }^{21}$ using molecular mechanics (MMFF). About 200 different conformers were obtained for each isomer, which were reoptimized using semiempirical methods (AM1). All the conformers were further optimized at the HF/3-21G ab initio level. The lowest-energy conformers were succesively optimized at the $\mathrm{HF} / 6-31 \mathrm{G}(\mathrm{d}, \mathrm{p})$ and B3LYP/6-31G(d,p) levels of theory; vibrational analyses were performed on the sets of most stable conformers. All the ab initio calculations were carried out with Gaussian $94 .^{22}$ The final sets of conformers (thirteen for $\mathbf{5 c}$ and eleven for $\mathbf{6 c}$ ) obtained at the B3LYP/6$31 \mathrm{G}(\mathrm{d}, \mathrm{p})$ level consisted of those within the lowest $2 \mathrm{kcal}$ of energy, relative to the most stable geometries. The vicinal coupling constants $\left({ }^{3} J_{\mathrm{HH}}\right) \mathrm{H}-2 / \mathrm{H} 3 \mathrm{a}$ and $\mathrm{H}-2 / \mathrm{H}-3 \mathrm{~b}$ were estimated for all the conformers from the corresponding dihedral angles of the calculated conformers, using the Haasnoot-de Leeuw-Altona equation for three substituents, ${ }^{23}$ as implemented in the Mestre-J program. ${ }^{24}$ We assumed that the most stable conformers of the diastereomeric pair $\mathbf{5} \mathbf{b} / \mathbf{6} \mathbf{b}$ would be very similar to those of $\mathbf{5} \mathbf{c} / \mathbf{6 c}$, in terms of their structural analogy and the similarity in the NMR data of both sets of compounds.

The lowest energy conformers found for $\mathbf{5 c / 6 c}$ are shown in Figure 2. In principle, it would be expected that the formation of an intramolecular hydrogen bond, between the amine hydrogen and one or more of the four oxygen atoms, led to conformational stabilization. Indeed, most of the low-energy conformers analyzed show an oxygen in close proximity to the N-H bond. In particular, two lowest-energy conformers of 5c and the two lowest-energy conformers of $\mathbf{6 c}$ (and 
several others of the studied set) have the ester oxygen of the unsaturated group in close proximity to the N-H bond, as can be seen in Figure 2; however, the O-HN distance is somewhat longer than in a typical hydrogen bond. It is interesting to notice that even though several cyclic hydrogen bonds could be formed, with ring sizes ranging from 5 to 7 , the most stable structures correspond to a 5-membered ring. The structure of these molecules could also suggest that a larger stabilization would be obtained by simultaneous interaction of the NH bond with two oxygen atoms. However, none of the most stable conformers showed this feature.
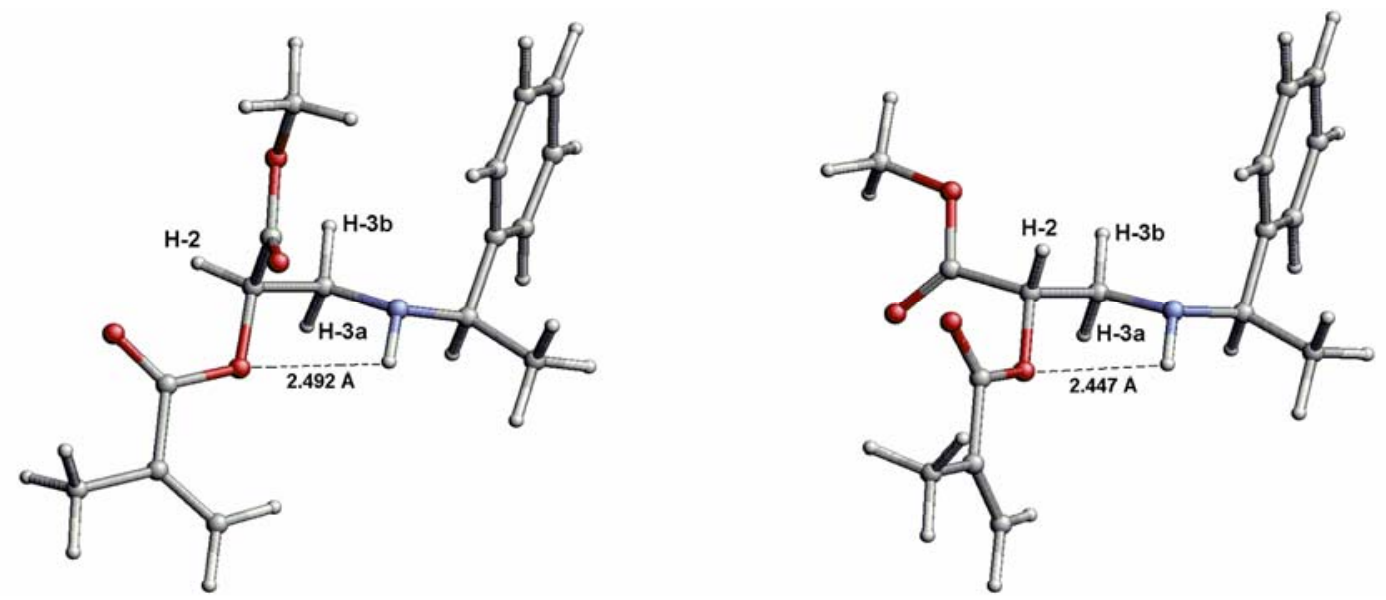

Figure 2. Lowest energy conformers (B3LYP/6-31G(d,p)) obtained for 5c (left) and 6c (right).

Table 5 shows the relative energies (B3LYP/6-31G(d,p)) of the most stable conformers of 5c and $\mathbf{6 c}$, the $\mathrm{H} 2-\mathrm{H} 3 \mathrm{a}$ and $\mathrm{H} 2-\mathrm{H} 3 \mathrm{~b}$ dihedral angles for each conformer, and the corresponding coupling constants, calculated as described previously. It is immediately apparent that none of the conformers has a set of calculated coupling constants that is in accord with the experimental results. In particular, the $\mathrm{H} 2-\mathrm{H} 3 \mathrm{a}$ and $\mathrm{H} 2-\mathrm{H} 3 \mathrm{~b}$ coupling constants of the lowest energy conformers shown in Figure 2 are very similar for $\mathbf{5 c}$, and very different for $\mathbf{6 c}$, being this the result of the different spatial arrangement of the protons in both conformers.

The small energy differences among the conformers in each molecule, the differences in coupling constants observed among the different geometries (Table 5), and the fact that the NMR signals of the protons under analysis are very well defined, suggested a rapid conformational interconversion. In order to prove this hypothesis we decided to determine averaged coupling constants from the relative energies, assuming a Boltzmann distribution of conformers; these results are also included in Table 5.

Even though the numeric values of the calculated coupling constants do not quite agree with the experimental results (Table 1), the trends in both sets of coupling constants are similar, suggesting that our hypothesis is correct. It is expected that the conformational behaviour in solution be somewhat different from that in the gas phase, leading to a different energy for each conformer and hence a different conformer population which, in turn, would manifest itself in a 
slightly different set of coupling constants. From the experimental coupling constants one can estimate the averaged dihedral angles in the fragment of interest. For $\mathbf{5 c}$, the best combination of dihedral angles that fits the nOe data is $\theta_{\mathrm{H} 2-\mathrm{H} 3 \mathrm{a}}=51.4^{\circ}$ and $\theta_{\mathrm{H} 2-\mathrm{H} 3 \mathrm{~b}}=126.1^{\circ}$, while for $\mathbf{6 c}$ we have $\theta_{\mathrm{H} 2-\mathrm{H} 3 \mathrm{a}}=-126.1^{\circ}$ and $\theta_{\mathrm{H} 2-\mathrm{H} 3 \mathrm{~b}}=-44.6^{\circ}$.

Table 5. Relative energies ( $\mathrm{kcal} / \mathrm{mol}$ ), relative conformational populations, $\mathrm{H} 2-\mathrm{H} 3 \mathrm{a}$ and $\mathrm{H} 2-\mathrm{H} 3 \mathrm{~b}$ dihedral angles $\left(\theta\right.$, degrees), and calculated coupling constants for $\mathbf{5 c}$ and $\mathbf{6 c}\left({ }^{3} \mathrm{~J}, \mathrm{~Hz}\right)$, obtained from the B3LYP/6-31G(d,p) optimized geometries.

\begin{tabular}{|c|c|c|c|c|c|c|}
\hline Conformer & $\begin{array}{l}\text { Relative } \\
\text { energy }^{a}\end{array}$ & $\begin{array}{c}\text { Relative } \\
\text { population }^{b}\end{array}$ & $\begin{array}{c}\theta \\
(\mathrm{H} 2-\mathrm{H} 3 \mathrm{a}) \\
\end{array}$ & $\begin{array}{c}{ }^{3} J \\
(\mathrm{H} 2-\mathrm{H} 3 \mathrm{a})\end{array}$ & $\begin{array}{c}\theta \\
(\mathrm{H} 2-\mathrm{H} 3 \mathrm{~b})\end{array}$ & $\begin{array}{c}{ }^{3} J \\
(\mathrm{H} 2-\mathrm{H} 3 \mathrm{~b})\end{array}$ \\
\hline $5 c-01$ & 0.000 & 1.000 & -61.62 & 3.33 & 54.24 & 2.14 \\
\hline $5 c-02$ & 0.113 & 0.826 & -60.31 & 3.49 & 55.56 & 2.00 \\
\hline $5 c-03$ & 0.165 & 0.756 & 174.89 & 10.98 & -69.52 & 3.23 \\
\hline $5 c-04$ & 0.376 & 0.530 & 62.97 & 2.29 & 179.15 & 11.01 \\
\hline $5 c-05$ & 0.612 & 0.356 & 62.89 & 2.30 & 179.06 & 11.01 \\
\hline $5 c-06$ & 0.643 & 0.337 & -60.57 & 3.45 & 55.50 & 2.01 \\
\hline $5 c-07$ & 0.844 & 0.241 & -59.44 & 3.59 & 56.65 & 1.89 \\
\hline $5 c-08$ & 0.887 & 0.224 & 63.34 & 2.26 & 179.45 & 10.99 \\
\hline $5 c-09$ & 0.969 & 0.195 & 63.46 & 2.25 & 179.33 & 11.00 \\
\hline $5 c-10$ & 1.148 & 0.144 & 63.15 & 2.28 & 179.23 & 11.00 \\
\hline $5 c-11$ & 1.195 & 0.133 & 63.39 & 2.26 & 179.25 & 11.00 \\
\hline $5 c-12$ & 1.491 & 0.081 & 169.41 & 10.85 & -75.45 & 2.53 \\
\hline $5 c-13$ & 1.671 & 0.060 & 169.40 & 10.85 & -75.47 & 2.53 \\
\hline Average $^{c 3} J$ & & & & 4.44 & & 5.15 \\
\hline $6 c-01$ & 0.000 & 1.000 & -179.34 & 11.00 & -63.10 & 2.28 \\
\hline $6 c-02$ & 0.259 & 0.645 & -179.34 & 11.00 & -63.09 & 2.28 \\
\hline $6 c-03$ & 0.422 & 0.491 & -54.18 & 2.15 & 61.63 & 3.33 \\
\hline $6 c-04$ & 0.641 & 0.339 & -55.43 & 2.02 & 60.41 & 3.47 \\
\hline $6 c-05$ & 0.693 & 0.311 & -179.63 & 10.94 & -63.55 & 2.24 \\
\hline $6 c-06$ & 0.768 & 0.273 & -54.81 & 2.08 & 60.81 & 3.42 \\
\hline $6 c-07$ & 1.163 & 0.140 & -58.05 & 1.76 & 57.62 & 3.82 \\
\hline $6 c-08$ & 1.323 & 0.107 & -178.06 & 11.07 & -62.37 & 2.28 \\
\hline $6 c-09$ & 1.464 & 0.084 & 72.84 & 2.83 & -172.36 & 10.94 \\
\hline $6 c-10$ & 1.874 & 0.042 & 56.66 & 5.02 & 172.51 & 10.67 \\
\hline $6 c-11$ & 2.077 & 0.030 & 55.91 & 5.13 & 171.63 & 10.61 \\
\hline Average $^{c{ }^{3} J}$ & & & & 7.46 & & 3.08 \\
\hline
\end{tabular}

${ }^{a}$ From the electronic energies and including zero-point and Gibbs free-energy corrections, assuming $\mathrm{T}=298 \mathrm{~K}$ and $\mathrm{P}=1 \mathrm{~atm} .{ }^{b}$ Calculated as $e^{-\varepsilon} \mathrm{i} / \mathrm{RT}$, where $\varepsilon_{\mathrm{i}}$ is the relative energy of each conformer. ${ }^{c}$ Calculated as $\Sigma_{\mathrm{i}}\left(J_{i} e^{-\varepsilon} \mathrm{i} / \mathrm{RT}\right) / \Sigma_{\mathrm{i}} e^{-\varepsilon} \mathrm{i} / \mathrm{RT}$, where $J_{\mathrm{i}}$ is the calculated coupling constant of each conformer. 
In summary, a new synthetic approach for the preparation of chiral $\alpha$-hydroxy- $\beta$-amino acids was described. This was based on the diastereoselective addition of the $(R)-(+)-$ methylbenzylamine (4a) to the captodative olefins 1a-1c. The diastereoselectivity was improved by addition of the lithium amide of $\mathbf{4 a}$ to the alkene 1a, assisted by the presence of alkyl- and alkylphenylsilyl chlorides (8a-8c). The best conditions were found by using $t$-butyldimethylsilyl chloride (8a) in ethyl ether, to give the $(R)$ adduct $\mathbf{5 a}$ as the main diasteroisomer. Competitive addition of the amide to the ester group belonging to the electron-releasing group of the olefins 1a and 1b was also observed. An improved preferential 1,4-addition of the chiral amine to the conjugate moiety was successfully obtained by changing the aroyloxy group of $\mathbf{1 a}$ and $\mathbf{1 b}$ by the methacryloxy group of the olefin 1c; however, the diastereoselectivity was lower. A higher chemoselective and, perhaps, also diastereoselective addition might be carried out by the use of an alkoxy group, instead of the aroyloxy group as the electron-donating group in captodative olefins $\mathbf{1}$, which is not susceptible to undergo addition from amines. Studies focused toward this direction have been undergone, and the results will be reported in due course.

\section{Experimental Section}

General Procedures. Melting points (uncorrected) were determined with an Electrothermal capillary melting point apparatus. IR spectra were recorded on a Perkin-Elmer 1600 spectrophotometer. ${ }^{1} \mathrm{H}(300 \mathrm{MHz})$ and ${ }^{13} \mathrm{C}(75.4 \mathrm{MHz})$ NMR spectra were recorded on a Varian Mercury-300 instrument, in $\mathrm{CDCl}_{3}$ as solvent and TMS as internal standard. Mass spectra (MS) and HRMS were obtained, in electron impact (EI) $(70 \mathrm{eV})$ and fast atom bombardment (FAB) modes, on a Hewlett-Packard 5971A, and on a Jeol JMS-AX 505 HA spectrometers. Microwave irradiation was carried out in a variable output (power in Watts) microwave oven MIC-1 from SEV (Mexico). ${ }^{25}$ Analytical thin-layer chromatography was performed using E. Merck silica gel $60 \mathrm{~F}_{254}$ coated 0.25 plates, visualizing by long- and short-wavelength UV lamps. Radial chromatography was performed on a Chromatotron of Harrison Research Instruments. All air moisture sensitive reactions were carried out under nitrogen using oven-dried glassware. Ethyl ether and THF were freshly distilled from sodium, and methylene chloride from calcium hydride, prior to use. All other reagents were used without further purification. Olefin 1a was prepared as reported. $^{12 \mathrm{~b}}$

Methyl 2-(4-bromobenzoyloxy)-2-propenoate (1b). To a solution of $6.0 \mathrm{~mL}(0.043 \mathrm{~mol})$ of triethylamine in dry THF $(20 \mathrm{~mL})$ and HMPA $(1.0 \mathrm{~mL})$, at $-10{ }^{\circ} \mathrm{C}$ and under an $\mathrm{N} 2$ atmosphere, $2.0 \mathrm{~g}(19.6 \mathrm{mmol})$ of methyl pyruvate in dry THF $(15 \mathrm{~mL})$ were added dropwise Then, at the same temperature, $3.0 \mathrm{~g}$ (13.7 $\mathrm{mmol})$ of 4-bromobenzoyl chloride diluted in dry THF (15 mL) were slowly added. After being stirred at room temperature for $24 \mathrm{~h}$, the solvent was removed under vacuum, the residue was dissolved in $\mathrm{CH}_{2} \mathrm{Cl} 2(60 \mathrm{~mL})$, and the organic solution was washed with an aqueous saturated solution of $\mathrm{NH} 4 \mathrm{Cl}(2 \times 50 \mathrm{~mL})$. The aqueous layer was 
extracted with $\mathrm{CH}_{2} \mathrm{Cl} 2(3 \times 50 \mathrm{~mL})$. The combined organic extracts were dried $(\mathrm{MgSO} 4)$, and the solvent was evaporated under vacuum. The residue was successively purified by flash column chromatography on silica gel (30 g, hexane/EtOAc, 95:5), and by radial chromatography (hexane/EtOAc, 90:10), to give $1.95 \mathrm{~g} \mathrm{(35 \% )} \mathrm{of} \mathrm{2a} \mathrm{as} \mathrm{a} \mathrm{colorless} \mathrm{oil.} \mathrm{Rf} 0.3$ (hexane/EtOAc, 8:2). IR (film) 1737, 1648, 1483, 1440, 1307, 1265, 1195, 1151, 1079, $1010 \mathrm{~cm}-1$; 1H NMR (300 $\mathrm{MHz}, \mathrm{CDCl} 3) \delta 3.82(\mathrm{~s}, 3 \mathrm{H}, \mathrm{CO} 2 \mathrm{CH} 3), 5.63$ (d, J=1.8 Hz, 1H, H-3), 6.18 (d, J=1.8 Hz, 1H, H3), 7.61-7.66 (m, 2H, ArH), 7.95-8.00 (m, 2H, ArH); 13C NMR (75.4 MHz, CDCl3) $\delta 52.7$ (CO2CH3), 114.5 (C-3), 127.4 (Ar), 129.1 (Ar), 131.7 (ArH), 132.0 (ArH), 144.5 (C-2), 161.8 $(\mathrm{CO} 2 \mathrm{CH} 3), 164.0(\mathrm{PhCO} 2)$. HRMS (FAB, $\mathrm{M}+)$ ( $m \mathrm{NBA})$ : calcd. for $\mathrm{C} 11 \mathrm{H} 10 \mathrm{BrO} 4:$ 284.9762; found: 284.9771 .

Methyl 2-(methacryloxy)-2-propenoate (1c). To a solution of $5.0 \mathrm{~mL}(0.036 \mathrm{~mol})$ of triethylamine in dry THF $(20 \mathrm{~mL})$ and HMPA $(1.0 \mathrm{~mL})$, at $-50{ }^{\circ} \mathrm{C}$ and under an $\mathrm{N} 2$ atmosphere, $3.5 \mathrm{~g}$ (33.5 mmol) of methacryloyl chloride diluted in dry THF $(15 \mathrm{~mL})$ were slowly added. At the same temperature, $2.0 \mathrm{~g}(19.6 \mathrm{mmol})$ of methyl pyruvate in dry THF $(15 \mathrm{~mL})$ were added dropwise. After being stirred at room temperature for $24 \mathrm{~h}$, the solvent was removed under vacuum, the residue was dissolved in $\mathrm{CH}_{2} \mathrm{Cl}_{2}(60 \mathrm{~mL})$, and the organic solution was washed with an aqueous saturated solution of $\mathrm{NH} 4 \mathrm{Cl}(2 \times 50 \mathrm{~mL})$. The aqueous layer was extracted with $\mathrm{CH} 2 \mathrm{Cl} 2(3 \times 50 \mathrm{~mL})$. The combined organic extracts were dried (MgSO4), and the solvent was evaporated under vacuum. The residue was purified by flash column chromatography on silica gel (30 g, hexane/EtOAc, 95:5), to give $3.0 \mathrm{~g}(90 \%)$ of $1 \mathrm{c}$ as a colorless oil. Rf 0.57 (hexane/EtOAc, 8:2). IR (film) 1737, 1647, 1442, 1301, 1195, 1129 cm-1; 1H NMR (300 MHz, $\mathrm{CDCl} 3$ ) $\delta 2.01$ (br s, 3H, $\mathrm{MeC}=$ ), 3.81 (s, 3H, CO2CH3), 5.52 (d, $J=1.8 \mathrm{~Hz}, 1 \mathrm{H}, \mathrm{H}-3$ ), 5.77-5.73 $(\mathrm{m}, 1 \mathrm{H}, \mathrm{CH} 2=), 6.09(\mathrm{~d}, J=1.8 \mathrm{~Hz}, 1 \mathrm{H}, \mathrm{H}-3), 6.30(\mathrm{~d}, J=1.8 \mathrm{~Hz}, 1 \mathrm{H}, \mathrm{CH} 2=)$; 13C NMR $(75.4$ $\left.\mathrm{MHz}, \mathrm{CDCl}_{3}\right) \delta 18.0(\mathrm{CH} 3 \mathrm{C}=), 52.4(\mathrm{CO} 2 \mathrm{CH} 3), 113.9(\mathrm{C}-3), 127.8(\mathrm{CH} 2=), 134.7(\mathrm{CH} 3 C=)$, 144.5 (C-2), 161.8 (CO2CH3), 165.2 (=CMeCO2). (206.2): HRMS (FAB, $\mathrm{MH}+$ ) ( $m \mathrm{NBA})$ : calcd. for $\mathrm{C} 8 \mathrm{H} 11 \mathrm{O} 4: 171.0657$; found: 171.0649 .

Methyl (2R)-3-[(R)-Methylbenzylamino]-2-(4-nitrobenzoyloxy)propenoate (5a). Methyl (2S)-3-[(R)-methylbenzylamino]-2-(4-nitrobenzoyloxy)propenoate (6a). Method A. To a solution of $0.5 \mathrm{~g}(1.99 \mathrm{mmol})$ of $1 \mathrm{a}$ in dry THF $(3 \mathrm{~mL})$, at room temperature, $0.48 \mathrm{~g}(3.97 \mathrm{mmol})$ of $(R)-(+)$-methylbenzylamine (4a) were added. After being stirred at room temperature for $4 \mathrm{~h}$, and the solvent was removed under vacuum. The residue (a mixture of $\mathbf{5 a}+\mathbf{6} \mathbf{a} / \mathbf{7} \mathbf{a}, 70: 30$ ) was purified by flash column chromatography on silica gel (15 g, hexane/EtOAc, 100:2), to give 0.25 $\mathrm{g}(46 \%)$ of a mixture of $\mathbf{5 a} / \mathbf{6 a}(60: 40)$ as a pale yellow oil.

Method B. To a solution of $0.24 \mathrm{~g}(2.00 \mathrm{mmol})$ of $4 \mathbf{a}$ in dry THF $(10 \mathrm{~mL})$, at room temperature, $2.00 \mathrm{mmol}$ of the corresponding silyl chloride 8a-8c were added. After being stirred at room temperature for $1 \mathrm{~h}$, the mixture was cooled to $-50^{\circ} \mathrm{C}$, and $0.128 \mathrm{~g}(2.00 \mathrm{mmol})$ of $n$-BuLi $(2 \mathrm{M}$ solution in hexane) were added dropwise. At the same temperature, $0.251 \mathrm{~g}(1.00 \mathrm{mmol})$ of $1 \mathrm{a}$ in dry THF $(5 \mathrm{~mL})$ were added. The mixture was stirred at $-50^{\circ} \mathrm{C}$ for $4 \mathrm{~h}$, then at $25^{\circ} \mathrm{C}$ for $24 \mathrm{~h}$. The mixture was extracted with $\mathrm{CH}_{2} \mathrm{Cl} 2(3 \times 30 \mathrm{~mL})$, and the combined organic extracts were washed with an aqueous saturated solution of $\mathrm{NH} 4 \mathrm{Cl}(2 \times 30 \mathrm{~mL})$ and with brine $(30 \mathrm{~mL})$. The 
organic layer was dried (MgSO4), and the solvent was evaporated under vacuum. The residue was purified by flash column chromatography on silica gel (15 g, hexane/EtOAc, 100:2), to give a mixture of $\mathbf{5 a} / \mathbf{6} \mathbf{a}$ as a pale yellow oil.

Method C. Following method B, and using $0.22 \mathrm{~g}(2.0 \mathrm{mmol})$ of trimethylsilyl chloride (8a), afforded $0.212 \mathrm{~g}(63 \%)$ of a mixture of $\mathbf{5 a} / \mathbf{6 a}(63: 37)$.

Method D. Following method B, and using $0.3 \mathrm{~g}(2.0 \mathrm{mmol})$ of $t$-butyldimethylsilyl chloride $(\mathbf{8 b})$, afforded $0.232 \mathrm{~g}(78 \%)$ of a mixture of $\mathbf{5 a} / \mathbf{6 a}(69: 31)$.

Method E. Following method B, and using $0.46 \mathrm{~g}(2.0 \mathrm{mmol})$ of diphenylmethylsilyl chloride $(\mathbf{8 c})$, afforded $0.166 \mathrm{~g}(61 \%)$ of a mixture of $\mathbf{5 a} / \mathbf{6 a}(69: 31)$. Isomer 5a was separated by radial chromatography (hexane/EtOAc, 100:2) as a colorless oil. Rf 0.31 (hexane/EtOAc, 8:2); [ $\alpha] \mathrm{D} 30=$ $-27.69(\mathrm{c}=0.13, \mathrm{MeOH})$. IR (film) 3350, 1735, 1603, 1525, 1345, 1267, $1104 \mathrm{~cm}-1$; 1H NMR $(300 \mathrm{MHz}, \mathrm{CDCl} 3) \delta 1.36(\mathrm{~d}, J=6.6 \mathrm{~Hz}, 3 \mathrm{H}, \mathrm{CH} 3 \mathrm{CHN}), 1.70(\mathrm{br} \mathrm{s}, 1 \mathrm{H}, \mathrm{NH}), 3.02(\mathrm{dd}, J=13.2$, $6.2 \mathrm{~Hz}, 1 \mathrm{H}, \mathrm{H}-3 \mathrm{~b}$ ), 3.13 (dd, $J=13.2,3.4 \mathrm{~Hz}, 1 \mathrm{H}, \mathrm{H}-3 \mathrm{a}$ ), 3.76 (s, $3 \mathrm{H}, \mathrm{CO} 2 \mathrm{CH} 3$ ), 3.84 (q, $J=6.6$ $\mathrm{Hz}, 1 \mathrm{H}, \mathrm{H}-4), 5.42$ (dd, $J=6.2,3.4 \mathrm{~Hz}, 1 \mathrm{H}, \mathrm{H}-2), 7.24-7.38$ (m, 5H, PhH), 8.22-8.36 (m, 4H. ArH). Signals attributed to 6a: $3.74\left(\mathrm{~s}, \mathrm{CO}_{2} \mathrm{CH} 3\right) ; 13 \mathrm{C} \mathrm{NMR}(75.4 \mathrm{MHz}, \mathrm{CDCl} 3) \delta 24.8(\mathrm{CH} 3 \mathrm{C}-$ 4), 47.5 (C-3), 52.5 (CO2CH3), $57.8(\mathrm{C}-4), 73.5(\mathrm{C}-2), 123.6(\mathrm{ArH}), 126.6(\mathrm{PhH}), 127.2(\mathrm{PhH})$, $128.5(\mathrm{PhH}), 131.0(\mathrm{ArH}), 134.7(\mathrm{Ar}), 144.7(\mathrm{Ph}), 150.7(\mathrm{Ar}), 164.1(\mathrm{ArCO} 2), 168.9\left(\mathrm{CO}_{2} \mathrm{CH} 3\right)$; MS (70 eV) m/z 372 (M+, 2), 357 ( 6), 283 (4), 270 (5), 167 (25), 150 (19), 134 (24), 121 (11), 105 (100), 77 (11), 65 (14). HRMS (FAB, MH+) ( $m$ NBA): calcd for C19H20N2O6: 373.2339; found 373.2346 .

Methyl (2R)-2-(4-bromobenzoyloxy)-3-[(R)-Methylbenzylamino]propenoate (5b). Methyl (2S)-2-(4-bromobenzoyloxy)-3-[(R)-Methylbenzylamino]propenoate (6b). Following method A of preparation of $\mathbf{5 a} / \mathbf{6 a}$, with $0.285 \mathrm{~g}(1.00 \mathrm{mmol})$ of $\mathbf{1 b}$ in dry THF $(2 \mathrm{~mL})$ and $0.242 \mathrm{~g}(2.00$ mmol) of $\mathbf{4 a}$, gave a mixture of $\mathbf{5 b}+\mathbf{6} \mathbf{b} / \mathbf{7 b}, 70 / 30$, which was separated by flash column chromatography on silica gel (10 g, hexane/EtOAc, 100:2), to give $0.205 \mathrm{~g}(50 \%)$ of $\mathbf{5 b} / \mathbf{6 b}$ (56:44) as a pale yellow oil. The latter were separated by flash column chromatography on silica gel (15 g, hexane/EtOAc, 100:2), to give $0.067 \mathrm{~g}(16 \%)$ of $\mathbf{5 b}$ and $0.026 \mathrm{~g}(6 \%)$ of $\mathbf{6 b}$ as colorless oils. Data of 5b: $R f 0.38$ (hexane/EtOAc, 8:2); [ $\alpha] \mathrm{D} 25=+23.24$ (c $=0.67$, EtOH). IR (film) 3334, 1726, 1590, 1446, 1358, 1266, 1215, 1107, $1012 \mathrm{~cm}-1$; 1H NMR (300 MHz, CDCl3) $\delta 1.36(\mathrm{~d}, J=6.6 \mathrm{~Hz}, 3 \mathrm{H}, \mathrm{CH} 3 \mathrm{CHN}), 2.98(\mathrm{dd}, J=12.9,6.0 \mathrm{~Hz}, 1 \mathrm{H}, \mathrm{H}-3 \mathrm{~b}), 3.02(\mathrm{br} \mathrm{s}, 1 \mathrm{H}, \mathrm{NH})$, 3.09 (dd, $J=12.9,3.6 \mathrm{~Hz}, 1 \mathrm{H}, \mathrm{H}-3 \mathrm{a}$ ), 3.74 (s, 3H, CO2CH3), 3.84 (q, $J=6.6 \mathrm{~Hz}, 1 \mathrm{H}, \mathrm{H}-4), 5.38$ (dd, $J=6.0,3.6 \mathrm{~Hz}, 1 \mathrm{H}, \mathrm{H}-2), 7.24-7.37$ (m, 5H, PhH), 7.58-7.64 (m, 2H, ArH), 7.90-7.97 (m, 2H, $\mathrm{ArH}$ ); 13C NMR (75.4 MHz, CDCl3) \& 24.6 (CH3C-4), $47.5(\mathrm{C}-3), 52.3\left(\mathrm{CO}_{2} \mathrm{CH} 3\right), 57.7$ (C4), 72.7 (C-2), $126.6(\mathrm{PhH}), 127.2(\mathrm{PhH}), 128.2(\mathrm{Ar}), 128.5(\mathrm{PhH}), 128.6(\mathrm{Ar}), 131.4(\mathrm{ArH})$, $131.8(\mathrm{ArH}), 144.6(\mathrm{Ph}), 165.1(\mathrm{ArCO} 2), 169.2\left(\mathrm{CO}_{2} \mathrm{CH} 3\right)$. HRMS (FAB, $\left.\mathrm{MH}+\right)(\mathrm{mNBA})$ : calcd for C19H21BrNO4: 406.0654; found 406.0649. Data of 6b: Rf 0.32 (hexane/EtOAc, 8:2); [a]D25 $=+30.38(\mathrm{c}=0.26$, EtOH). IR (film) 3337, 1726, 1589, 1446, 1365, 1266, 1214, 1175, 1106, $1065,1012 \mathrm{~cm}-1 ; 1 \mathrm{H}$ NMR (300 MHz, CDCl3) $\delta 1.38$ (d, $J=6.3 \mathrm{~Hz}, 3 \mathrm{H}, \mathrm{CH} 3 \mathrm{CHN}), 3.02(\mathrm{dd}, J$ $=12.9,4.0 \mathrm{~Hz}, 1 \mathrm{H}, \mathrm{H}-3 \mathrm{~b}), 3.12$ (dd, $J=12.9,6.3 \mathrm{~Hz}, 1 \mathrm{H}, \mathrm{H}-3 \mathrm{a}), 3.76$ (s, $3 \mathrm{H}, \mathrm{CO} 2 \mathrm{CH} 3), 3.85$ (q, $J=6.3 \mathrm{~Hz}, 1 \mathrm{H}, \mathrm{H}-4), 4.02$ (br s, 1H, NH), 5.34 (dd, $J=6.3,4.0 \mathrm{~Hz}, 1 \mathrm{H}, \mathrm{H}-2), 7.21-7.36$ (m, $5 \mathrm{H}$, 
$\mathrm{PhH})$, 7.57-7.63 (m, 2H, ArH), 7.89-7.95 (m, 2H, ArH); 13C NMR (75.4 MHz, CDCl3) $\delta 24.0$ (CH3C-4), $47.4(\mathrm{C}-3), 52.5(\mathrm{CO} 2 \mathrm{CH} 3), 57.9(\mathrm{C}-4), 72.7(\mathrm{C}-2), 126.5(\mathrm{PhH}), 127.3(\mathrm{PhH}), 128.1$ (Ar), $128.60(\mathrm{PhH}), 128.63(\mathrm{Ar}), 131.4(\mathrm{ArH}), 131.8(\mathrm{ArH}), 144.5(\mathrm{Ph}), 165.1(\mathrm{ArCO} 2), 169.3$ $(\mathrm{CO} 2 \mathrm{CH} 3)$. HRMS (FAB, $\mathrm{MH}+)(\mathrm{mNBA})$ : calcd for $\mathrm{C} 19 \mathrm{H} 21 \mathrm{BrNO} 4: 406.0654$; found 406.0647.

Methyl (2R)-2-(methacryloxy)-3-[(R)-methylbenzylamino]propenoate (5c). Methyl (2S)-2(methacryloxy)-3-[(R)-methylbenzylamino]propenoate (6c). Following method A of preparation of $\mathbf{5 a} / \mathbf{6 a}$, with $3.0 \mathrm{~g}(17.64 \mathrm{mmol})$ of $\mathbf{1 c}$ in dry THF $(6 \mathrm{~mL})$ and $2.66 \mathrm{~g}(22.0 \mathrm{mmol})$ of $4 \mathbf{a}$, gave a mixture of $\mathbf{5 c}+\mathbf{6} / 7 \mathbf{c}, 85: 15$, which was separated by flash column chromatography on silica gel ( $80 \mathrm{~g}$, hexane/EtOAc, 100:2), to give $3.55 \mathrm{~g} \mathrm{(71 \% )} \mathrm{of} \mathbf{5 c / 6 c}(56: 44)$ as a pale yellow oil. The latter were separated by flash column chromatography on silica gel (40 g, hexane/EtOAc, 100:2), to give $0.80 \mathrm{~g} \mathrm{(16 \% )}$ of $\mathbf{5 c}$ and $0.35 \mathrm{~g} \mathrm{(7 \% )}$ of $\mathbf{6 c}$ as colorless oils. Data of 5c: $R f 0.31$ (hexane/EtOAc, 8:2); [ $\alpha] \mathrm{D} 25=+80.00$ (c $=0.04$, EtOH). IR (film) 3338, 1758, $1724,1447,1304,1213,1157,1083 \mathrm{~cm}-1$; $1 \mathrm{H}$ NMR (300 MHz, CDCl3) $\delta 1.33$ (d, $J=6.3 \mathrm{~Hz}$, $3 \mathrm{H}, \mathrm{CH} 3 \mathrm{CHN}$ ), 1.63 (br s, 1H, NH), $2.00(\mathrm{~s}, 3 \mathrm{H}, \mathrm{MeC}=), 2.91(\mathrm{dd}, J=12.9,6.6 \mathrm{~Hz}, 1 \mathrm{H}, \mathrm{H}-3 \mathrm{~b})$, 2.99 (dd, $J=12.9,3.6 \mathrm{~Hz}, 1 \mathrm{H}, \mathrm{H}-3 \mathrm{a}$ ), 3.72 (s, 3H, CO2CH3), 3.80 (q, $J=6.3 \mathrm{~Hz}, 1 \mathrm{H}, \mathrm{H}-4), 5.20$ (dd, $J=6.6,3.6 \mathrm{~Hz}, 1 \mathrm{H}, \mathrm{H}-2), 5.66-5.70(\mathrm{~m}, 1 \mathrm{H}, \mathrm{CH} 2=), 6.22$ (br s, $1 \mathrm{H}, \mathrm{CH} 2=), 7.22-7.36(\mathrm{~m}$, $5 \mathrm{H}, \mathrm{PhH}) ; 13 \mathrm{C}$ NMR $(75.4 \mathrm{MHz}, \mathrm{CDCl} 3) \delta 18.3\left(\mathrm{CH}_{3} \mathrm{C}=\right), 20.4(\mathrm{CH} 3 \mathrm{C}-4), 44.5(\mathrm{C}-3), 53.0$ (CO2CH3), $58.8(\mathrm{C}-4), 67.6(\mathrm{C}-2), 127.8(\mathrm{PhH}), 128.4(\mathrm{PhH}), 129.5(\mathrm{PhH}), 134.7(\mathrm{CH} 2=), 135.5$ $(\mathrm{Me} C=)$, $144.1(\mathrm{Ph}), 166.2(\mathrm{CO} 2), 169.2\left(\mathrm{CO}_{2} \mathrm{CH} 3\right)$. HRMS (FAB, MH+) $(m \mathrm{NBA})$ : calcd for C16H22NO4: 292.1549; found 292.1541. Data of 6c: $R f 0.28$ (hexane/EtOAc, 8:2); [a]D31 = -8.23 (c = 0.34, EtOH). IR (film) 3348, 1754, 1724, 1661, 1448, 1300, 1211, 1157, $1077 \mathrm{~cm}-1 ; 1 \mathrm{H}$ NMR (300 MHz, CDCl3) $\delta 1.34$ (d, $J=6.3 \mathrm{~Hz}, 3 \mathrm{H}, \mathrm{CH} 3 \mathrm{CHN}), 1.67$ (br s, $1 \mathrm{H}, \mathrm{NH}), 1.98$ (s, 3H, $\mathrm{MeC}=), 2.93(\mathrm{dd}, J=12.9,4.5 \mathrm{~Hz}, 1 \mathrm{H}, \mathrm{H}-3 \mathrm{~b}), 3.01$ (dd, $J=12.9,6.6 \mathrm{~Hz}, 1 \mathrm{H}, \mathrm{H}-3 \mathrm{a}), 3.74(\mathrm{~s}, 3 \mathrm{H}$, $\mathrm{CO} 2 \mathrm{CH} 3$ ), 3.80 (q, $J=6.3 \mathrm{~Hz}, 1 \mathrm{H}, \mathrm{H}-4), 5.16$ (dd, $J=6.6,4.5 \mathrm{~Hz}, 1 \mathrm{H}, \mathrm{H}-2), 5.65-5.68$ (m, 1H, $\left.\mathrm{CH}_{2}=\right), 6.20($ br s, $1 \mathrm{H}, \mathrm{CH} 2=), 7.22-7.36(\mathrm{~m}, 5 \mathrm{H}, \mathrm{PhH}) ; 13 \mathrm{C} \mathrm{NMR}\left(75.4 \mathrm{MHz}, \mathrm{CDCl}_{3}\right) \delta 18.2$ $(\mathrm{CH} 3 \mathrm{C}=), 24.3(\mathrm{CH} 3 \mathrm{C}-4), 47.6(\mathrm{C}-3), 52.3\left(\mathrm{CO}_{2} \mathrm{CH} 3\right), 57.7(\mathrm{C}-4), 72.5(\mathrm{C}-2), 126.4(\mathrm{PhH})$, $126.7(\mathrm{PhH}), 127.1(\mathrm{PhH}), 128.5(\mathrm{CH} 2=), 135.4(\mathrm{Me} C=), 145.1(\mathrm{Ph}), 166.6(\mathrm{CO} 2), 169.6$ $(\mathrm{CO} 2 \mathrm{CH} 3)$. HRMS (FAB, $\mathrm{MH}+$ ) ( $m \mathrm{NBA}$ ): calcd for $\mathrm{C} 16 \mathrm{H} 22 \mathrm{NO} 4: 292.1549$; found 292.1555.

Theoretical calculations. For the determination of the charges of captodative olefins 1a-1d, several conformers were considered in terms of the known conformational preference of these molecules, in which the RCOO- group is almost perpendicular to the plane of the $\alpha, \beta$-unsaturated carbonyl group. ${ }^{26}$ We analyzed the conformations of the latter fragment (s-cis and s-trans) and, in the case of 1c, we also considered the s-cis and s-trans conformations of the methacryloyl group. The initial geometries were optimized at the RHF/3-21G ab initio level, and the resulting structures were employed as starting points for optimizations at the RHF/6-31G(d,p) level of theory. The Mülliken charges were obtained directly from these optimized geometries, considering only the "charges with hydrogens summed into heavy atoms".

For the conformational study, Monte Carlo and semiempirical calculations (AM1) were carried out with Spartan ${ }^{21}$ in a Digital Personal Workstation 500au under Digital Unix. The Merck Molecular Force Field (MMFF) was employed for conformational searches using a 
molecular dynamics algorithm, and considering two-fold (for the conjugated fragments) and three-fold rotational freedom of the single bonds of the molecules under consideration. The resulting geometries were further optimized first with the AM1 semiempirical method (Spartan), and then by ab initio methods at the HF/3-21G, HF/6-31G(d,p) and B3LYP/6-31G(d,p), using the geometries of the lower levels as starting points for optimization at the higher levels of theory. All the ab initio calculations were carried out using Gaussian $94^{22}$ in personal computers running under Linux. In all the ab initio optimizations the OPT=TIGHT keyword was employed; in addition, all the DFT calculations were carried out employing the INT(GRID=99590) keyword, in order to obtain better energies and vibrational frequencies. For all the conformers that we considered significant, additional vibrational analyses were carried out at each level of $a b$ initio theory. For the final results, the electronic energies of each conformer were corrected by the thermal Gibbs Free Energy correction term (at $298 \mathrm{~K}$ and $1 \mathrm{~atm}$ ), as given by the statistical mechanics analysis of the vibrational frequencies. Relative energies were obtained by substracting the energy of the lowest-energy conformer from the energies of all the conformers in each system, and converting these differences into $\mathrm{kcal} / \mathrm{mol}$. Additional details can be found in the main text.

\section{Acknowledgements}

We thank Fernando Labarrios for his help in spectrometric measurements. J.T. gratefully acknowledges DEPI/IPN (Grants 20030147, 2004123, and 20050151) and CONACYT (Grants 32273-E and 43508Q) for financial support. H.A.J.-V. thanks CONACYT (Grant 3251P) for financial support. R.H. is grateful to CONACYT for a graduate scholarship, and to the Ludwig K. Hellweg Foundation for a partial scholarship.

\section{References and Footnotes}

1. (a) Drey, C. N. C. In Chemistry and Biochemistry of Amino Acids, Barret, G. C., Ed. Chapman and Hall: London, 1985; p 25. (b) The Organic Chemistry of $\beta$-Lactams, Georg, G. I., Ed.; VCH: New York, 1993. (c) Tamariz, J. Biological Activity of $\beta$-Amino Acids and $\beta$-Lactams, In Enantioselective Synthesis of $\beta$-Amino Acids, Juaristi, E., Ed. Enantioselective Synthesis of $\beta$-Amino Acids, Wiley-VCH: New York, 1997; p 45. (d) Liu, M.; Sibi, M. P. Tetrahedron 2002, 58, 7991.

2. (a) Enantioselective Synthesis of $\beta$-Amino Acids, Juaristi, E., Ed.; Wiley-VCH: New York, 1997. (b) Juaristi, E.; Quintana, D.; Escalante, J. Aldrichim. Acta 1994, 27, 3.

3. (a) Taxane Anticancer Agents: Basic Science and Current Status, Georg, G. I.; Chen, T. T.; Ojima, I.; Vyas, D. M., Eds; American Chemical Society: Washington, D.C., 1995. (b) 
Taxol Science and Applications, Suffness, M., Ed.; CRC: Boca Raton, FL, 1995.(c) Patel, R. N. Curr. Org. Chem. 2003, 7, 1369.

4. Iizuka, K.; Kamijo, T.; Harada, H.; Akahane, K.; Kubota, T.; Umeyama, H.; Ishida, T.; Kiso, Y. J. Med. Chem. 1990, 33, 2707.

5. Hattori, K.; Miyata, M.; Yamamoto, H. J. Am. Chem. Soc. 1993, 115, 1151.

6. Denis, J.-N.; Greene, A. E.; Serra, A. A.; Luche, M.-J. J. Org. Chem. 1986, 51, 46.

7. (a) Deng, L.; Jacobsen, E. N. J. Org. Chem. 1992, 57, 4320. (b) Zhou, Z.; Mei, X. Synth. Commun. 2003, 33, 723.

8. (a) Denis, J.-N.; Correa, A.; Greene, A. E. J. Org. Chem. 1990, 55, 1957. (b) Koskinen, A. M. P.; Karvinen, E. K.; Siirilä, J. P. J. Chem. Soc., Chem. Commun. 1994, 21. (c) Voronkov, M. V.; Gontcharov, A. V.; Wang, Z.-M. Tetrahedron Lett. 2003, 44, 407.

9. (a) Davis, F. A.; Reddy, R. T.; Reddy, R. E. J. Org. Chem. 1992, 57, 6387.(b) Escalante, J.; Juaristi, E. Tetrahedron Lett. 1995, 36, 4397. (c) Bunnage, M. E.; Davies, S. G.; Goodwin, C. J. J. Chem. Soc., Perkin Trans. 1 1993, 1375. (d) Caputo, R.; Cecere, G.; Guaragna, A.; Palunbo, G.; Pedatella, S. Eur. J. Org. Chem. 2002, 3050.

10. For recent methods: (a) Tromp, R. A.; van der Hoeven, M.; Amore, A.; Brussee, J.; Overhand, M.; van der Marel, G. A.; van der Gen, A. Tetrahedron: Asymmetry 2003, 14, 1645. (b) Righi, G.; D’Achille, C; Pescatore, G.; Bonini, C. Tetrahedron Lett. 2003, 44, 6999.(c) Lee, J.-M.; Lim, H.-S.; Seo, K.-C.; Chung, S.-K. Tetrahedron: Asymmetry 2003, 14, 3639. (d) Borah, J. C.; Gogoi, S.; Boruwa, J.; Kalita, B.; Barua, N. C. Tetrahedron Lett. 2004, 45, 3689. (e) Galeazzi, R.; Martelli, G.; Mobbili, G.; Orena, M.; Rinaldi, S. Org. Lett. 2004, 6, 2571. (f) Kondekar, N. B.; Kandula, S. R. V.; Kumar, P. Tetrahedron Lett. 2004, 45, 5477. (g) Voronkov, M. V.; Gontcharov, A. V.; Wang, Z.-M.; Richardson, P. F.; Kolb, H. C. Tetrahedron 2004, 60, 9043.

11. (a) Reyes, A. Aguilar, R.; Muñoz, A. H.; Zwick, J.-C.; Rubio, M.; Escobar, J.-L.; Soriano, M.; Toscano, R.; Tamariz, J. J. Org. Chem. 1990, 55, 1024. (b) Herrera, R.; Nagarajan, A.; Morales, M. A.; Méndez, F.; Jiménez-Vázquez, H. A.; Zepeda, G.; Tamariz, J. J. Org. Chem. 2001, 66, 1252.

12. (a) Andrade, R. M.; Muñoz, A. H.; Tamariz, J. Synth. Commun. 1992, 22, 1603. (b) Orduña, A.; Zepeda, L. G.; Tamariz, J. Synthesis 1993, 375. (c) Ochoa, M. E.; Arias, M. S.; Aguilar, R.; Delgado, F.; Tamariz, J. Tetrahedron 1999, 55, 14535. (d) Aguilar, R.; Reyes, A.; Orduña, A.; Zepeda, G.: Bates, R. W.; Tamariz, J. Rev. Soc. Quím. Méx. 2000, 44, 91.

13. Herrera, R.; Jiménez-Vázquez, H. A.; Modelli, A.; Jones, D.; Söderberg, B. C.; Tamariz, J. Eur. J. Org. Chem. 2001, 4657.

14. (a) Srivastava, N.; Banik, B. K. J. Org. Chem. 2003, 68, 2109. (b) Hii, K. K.; Li, K. Chem. Commun. 2003, 1132. (c) Wabnitz, T. C.; Yu, J.-Q.; Spencer, J. B. Synlett 2003, 1070. (d) Naidu, B. N.; Sorenson, M. E.; Connolly, T. P.; Ueda, Y. J. Org. Chem. 2003, 68, 10098. (e) Takasu, K.; Nishida, N.; Ihara, M. Synlett 2004, 1844.

15. Davies, S. G.; Hermann, G. J.; Sweet, M. J.; Smith, A. D. Chem. Commun. 2004, 1128. 16. Moghaddam, F. M.; Mohammadi, M.; Hosseinnia, A. Synth. Commun. 2000, 30, 643. 
17. Kawatsura, M.; Hartwig, J. F. Organometallics 2001, 20, 1960.

18. Herrera, R.; Jiménez-Vázquez, Delgado, F.; Söderberg, B. C.; Tamariz, J. J. Braz. Chem. Soc., in press.

19. Sewald, N.; Hiller, K. D.; Körner, M.; Findeisen, M. J. Org. Chem. 1998, 63, 7263.

20. Asao, N.; Uyehara, T.; Yamamoto, Y. Tetrahedron 1990, 46, 4563.

21. Spartan Version 5.1.3. Wavefunction Inc. 18401 Von Karman. Suite 370. Irvine CA 92612.

22. Gaussian 94, Revision E.2, Frisch, M. J.; Trucks, G. W.; Schlegel, H. B.; Gill, P. M. W.; Johnson, B. G.; Robb, M. A.; Cheeseman, J. R.; Keith, T.; Petersson, G. A.; Montgomery, J. A.; Raghavachari, K.; Al-Laham, M. A.; Zakrzewski, V. G.; Ortiz, J. V.; Foresman, J. B.; Cioslowski, J.; Stefanov, B. B.; Nanayakkara, A.; Challacombe, M.; Peng, C. Y.; Ayala, P. Y.; Chen, W.; Wong, M. W.; Andres, J. L.; Replogle, E. S.; Gomperts, R.; Martin, R. L.; Fox, D. J.; Binkley, J. S.; Defrees, D. J.; Baker, J.; Stewart, J. P.; Head-Gordon, M.; Gonzalez, C.; Pople, J. A., Gaussian, Inc., Pittsburgh PA, 1995.

23. Haasnoot, C. A. G.; de Leeuw F. A. A. M.; Altona, C. Tetrahedron, 1980, 36, 2783.

24. MESTRELAB RESEARCH - Rúa Xosé Pasín 6 - 5C. Santiago de Compostela. A CORUÑA, SPAIN - CP 15706.

25. Web page: www.sevmexico.com

26. Jiménez-Vázquez, H. A.; Ochoa, M. E.; Zepeda, G.; Modelli, A.; Jones, D.; Mendoza, J. A.; Tamariz, J. J. Phys. Chem. A 1997, 101, 10082. 